\title{
Management control as a package-The need for international research
}

\author{
Teemu Malmi
}

C Springer-Verlag Berlin Heidelberg 2013

This special issue of JoMaC is devoted to various conceptualizations of management control systems. Management control systems have been one of the core topics of academic accounting research for decades. Given this relatively long tradition, national differences in managerial practices and somewhat isolated research communities until recent years, it is not surprising that there exist a number of different conceptualizations and interpretations of what control is, what are management control systems, what is a management system and how this is different from management control system, what is the role of a controller, and so on. On the other hand, it is also somewhat surprising that in today's global world these divergent views have not converged to a system of concepts we could all accept and use similarly as a basis of our academic and practical work. Perhaps this latter point just reminds us that there is not a large number of scholars around the globe working on these topics actively at any point in time and our field of research is not mature yet. Given the various philosophical approaches to research evident today, I doubt we never end up with a common and universal agreement. Nevertheless, I am hoping that words and concepts in our field would slowly start to reach a state where we do understand each other's when we use them.

A good example of this difficulty of concepts is the term "control package". It seems that attempts to clarify certain issues bring in new conceptual problems easily. To my understanding Otley used the concept "control package" initially to convey an idea that not all control systems are necessarily designed at the same time to work as a coherent whole, or systems existing in any firm at any point in time may not be all well coordinated. If they were, we could talk about system, either management control system or management system, depending on the scope, and its

T. Malmi (凶)

Aalto University School of Business, Runeberginkatu 22-24, 00100 Helsinki, Finland

e-mail: teemu.malmi@aalto.fi 
various sub-systems. If there is limited or no alignment, we cannot talk about one system, but a bunch of systems, or a package. Hence, it does not make sense to talk about optimal package design, if package by definition allows a potential misalignment between systems. We could talk about optimal management system design, if we perceive the idea of package as a holistic perspective on the different dimensions of management and control. At least we should be clear on what is the difference between a system and a package of systems, if we would like to discuss optimal designs. It should be self evident, that from a normative perspective we should look for optimal designs, but from an empirical perspective, as researchers of organizational practices, we should be sensitive that normative attempts within firms do not always succeed. Hence, to understand the functioning and outcomes of any particular system (e.g. accounting system) we need to pay attention to other parts of the whole system, or a package of systems, depending on their alignment.

My task here is not to suggest any resolution to our conceptual challenges. But I do suggest that these kind of special issues, where various conceptual frameworks are presented, compared and contrasted, do serve an important role in our journey to reach some form of common agreement on what these words mean for us. This special issue presents and compares German "controlling" approaches to the wide spread Anglo-American conceptualizations. It is hoped that such comparisons facilitate learning both in Anglo-American and German research circles. It is also worth noting that if in various geographical areas researchers and teachers have very different conceptual frameworks in use, and also the work of practitioners in those countries differ, we need to be sensitive to these differences when we compare and contrast research findings from these areas. Therefore it is of importance to understand how control is conceptualized in various parts of the world.

This special issue presents five papers, four conceptual ones and one empirical examination. The Paper by Eric Strauss and Christina Zecher provides a comprehensive overview and comparison of MCS conceptualizations presented in international textbooks and academic research literature published in English. It illustrates clearly the diversity of conceptualizations within Anglo-American based literature. The Paper by Thomas Guenther presents conceptualizations of "controlling" in German-speaking countries. He illustrates the similarities and differences between those conceptualizations and provides also a comparison with Anglo-American frameworks. Despite many similarities he also identifies a number of differences. Utz Schaeffer provides an overview of the developments of management accounting research in Germany before the current era of internationalization. Moreover, he analyses current forces shaping academic accounting research in Germany and provides some likely implications that are worth thinking for all of us. The fourth paper is a position statement by the International Controller Association (Internationaler Controller Verein, ICV) and the International Group of Controlling (IGC). It aims to provide an up-to-date view of the term "Controlling" and the role of the controller from the point of view of practitioners. It was chosen to contrast the above scholarly papers and views with that of practitioners. Although it may not represent fully the views of other professional organizations, it certainly provides a good view on how practicing professionals determine their own field. The only empirical paper in this Special issue is by Lucas Goretzki. He challenges us to think the reasons why managers use management ac- 
counting techniques. As the reviewed frameworks in this special issue illustrate, normally accounting is perceived to support decision-making, and to assist in a process of guiding subordinates within organisations. Lucas Goretzki's study suggests mangers use accounting also for self-control and self-constitution.

I would like to end this editorial by referring back to Utz Schaeffer's likely implications of internationalization on the German-speaking research community. Germanspeaking countries have a long tradition of controlling research and practice. This is something to be proud of. There is no reason why the low status of management accounting research in the US should be accepted in German-speaking countries. With the help of a relatively large German-speaking research community we could further strengthen the status of Europe as the power base and intellectual home of management accounting research. This research does not need to, nor it should, be distanced from practice. These developments are ultimately up to us.

Teemu Malmi

Special Issue Guest Editor and

International Editor of JoMaC 